\title{
Alkalibacterium thalassium sp. nov., Alkalibacterium pelagium sp. nov., Alkalibacterium putridalgicola sp. nov. and Alkalibacterium kapii sp. nov., slightly halophilic and alkaliphilic marine lactic acid bacteria isolated from marine organisms and salted foods collected in Japan and Thailand
}

\author{
Morio Ishikawa, ${ }^{1}$ Somboon Tanasupawat, ${ }^{2}$ Kazuyuki Nakajima, $^{1}$ \\ Hajime Kanamori, ${ }^{1}$ Shihomi Ishizaki, ${ }^{1}$ Kayo Kodama, ${ }^{1}$ \\ Akiko Okamoto-Kainuma, ${ }^{1}$ Yukimichi Koizumi, ${ }^{1}$ Yasushi Yamamoto ${ }^{1}$ \\ and Kazuhide Yamasato ${ }^{1}$ \\ 'Department of Fermentation Science, Faculty of Applied Bio-Science, Tokyo University of \\ Agriculture, 1-1 Sakuragaoka 1-chome, Setagaya-ku, Tokyo 156-8502, Japan \\ ${ }^{2}$ Department of Microbiology, Faculty of Pharmaceutical Sciences, Chulalongkorn University, \\ 254 Phayathai Road, Wangmai, Pathumwan, Bangkok 10330, Thailand
}

Correspondence

Morio Ishikawa

m1ishika@nodai.ac.jp 
The genus Alkalibacterium presently comprises four species: Alkalibacterium olivapovliticus (the type species; Ntougias \& Russell, 2001), Alkalibacterium psychrotolerans (Yumoto et al., 2004), Alkalibacterium iburiense (Nakajima et al., 2005) and Alkalibacterium indicireducens (Yumoto et al., 2008). These bacteria were isolated from artificial alkaline environments: A. olivapovliticus from the washwater of edible olives, and the other three species from polygonum indigo fermentation liquor. All of the species possess alkaliphilic and halophilic properties: their optimum $\mathrm{pH}$ for growth is between 9 and 11.5, and the optimal $\mathrm{NaCl}$ concentrations are 3-5, $0-10$ and 3-10\% (for each of three strains of A. olivapovliticus), 2-12\% (A. psychrotolerans), 3-13\% (A. iburiense) and 1-11\% (A. incidireducens). They produce lactic acid as the main product of glucose fermentation.

Previously, we isolated some slightly alkaliphilic and halophilic lactic acid bacteria from marine organisms. These organisms, members of the genera Marinilactibacillus (Ishikawa et al., 2003) and Halolactibacillus (Ishikawa et al., 2005), inhabit marine environments and grow preferably under physicochemical conditions found in seawater [total salt concentration, 3.2-3.8\% (w/v); $\mathrm{pH}$, 8.2-8.3 (surface)]. For these organisms, we proposed the term 'marine lactic acid bacteria' (Ishikawa et al., 2003). In the course of further isolation experiments of lactic acid bacteria from marine environments in the subtropical area of Japan and tropical Thailand, we isolated novel halophilic and alkaliphilic lactic acid bacteria, belonging phylogenetically to the genus Alkalibacterium, from decaying marine algae, decaying seagrass, raw fish, salted fish and a salted and fermented shrimp paste ('ka-pi'). Here we describe the taxonomic characterization of the isolates, for which the names Alkalibacterium thalassium sp. nov., Alkalibacterium pelagium sp. nov., Alkalibacterium putridalgicola sp. nov. and Alkalibacterium kapii sp. nov. are proposed.

The samples for isolation of lactic acid bacteria were decaying algae that were collected from a foreshore site near the Oujima Islet $\left(26^{\circ} 07^{\prime} \mathrm{N} 127^{\circ} 40^{\prime} \mathrm{E}\right)$ in Okinawa prefecture, a subtropical area of Japan, in September 1998, and living, raw or decaying algae and seagrass, shellfish, crabs and fish collected from a beach on Koh Samet (Samet Island; $12^{\circ} 34^{\prime} \mathrm{N} 101^{\circ} 27^{\prime} \mathrm{E}$ ) in Rayong province and from

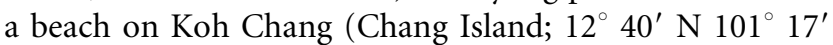
E) in Trat province, Thailand, in November 1998. The samples of salted fish and salted and fermented shrimp paste ('ka-pi') were obtained from markets in Bangkok and Rayong, Thailand, in November 1998.

The isolates of lactic acid bacteria were obtained by successive enrichment and subsequent pour-plating following procedures described previously (Ishikawa et al., 2003). For isolation from the samples collected in Thailand, a $7 \% \mathrm{NaCl}$ GYPF (glucose-yeast extractpeptone-fish extract) isolation broth for enrichment culture and a $7 \% \mathrm{NaCl}$ GYPF isolation agar (1.3\% agar) for pour-plating were used. The compositions of these media were as described previously (Ishikawa et al., 2003), except for $\mathrm{pH}$. The final $\mathrm{pH}$ was adjusted to 9.0 by supplementing the media with $6.1 \mathrm{~g} \mathrm{Na}_{2} \mathrm{CO}_{3} \mathrm{l}^{-1}$ and $8.9 \mathrm{~g}$ $\mathrm{NaHCO}_{3} \mathrm{l}^{-1}$. The first enrichment culture was incubated anaerobically at $30{ }^{\circ} \mathrm{C}$ for 3 days. For the second enrichment culture, broth medium was inoculated from the first enrichment culture, whose $\mathrm{pH}$ had decreased to $<7.0$, and incubated anaerobically at $30{ }^{\circ} \mathrm{C}$ for 2 days. In isolation experiments using the samples collected from Okinawa, Japan, $12 \% \mathrm{NaCl}$ GYPFSK broth ( $\mathrm{pH} 7.5$ ) was used for the first enrichment, which was incubated for 21 days, and $18 \% \mathrm{NaCl}$ GYPFSK isolation broth was used for the second enrichment, which was incubated for 15 days; both enrichment cultures were grown at $25{ }^{\circ} \mathrm{C}$ in standing culture. The compositions of the media and the procedures for isolation were as described previously (Ishikawa et al., 2003).

Ten strains of lactic acid bacteria used for study are described in Table 1, with sources, sites and dates of isolation. A. olivapovliticus NCIMB $13710^{\mathrm{T}}$, A. psychrotolerans JCM $12281^{\mathrm{T}}$, A. iburiense JCM $12662^{\mathrm{T}}, A$. indicireducens JCM $14232^{\mathrm{T}}$, Marinilactibacillus psychrotolerans $\mathrm{M} 13-2^{\mathrm{T}}$ and Marinilactibacillus piezotolerans JCM $12337^{\mathrm{T}}$ were used as reference strains. The isolates and reference strains were grown on $2.5 \% \mathrm{NaCl}$ GYPF agar (pH 9.0; $1.3 \%$ agar) or in $2.5 \% \mathrm{NaCl}$ GYPF broth (pH 9.0; Ishikawa et al., 2003) at $30{ }^{\circ} \mathrm{C}$ unless described otherwise. Anaerobic cultivation was conducted by using AnaeroPack-Keep (not $\mathrm{CO}_{2}$-generated; Mitsubishi Gas Chemical) as described previously (Ishikawa et al., 2003).

The methods for characterization of conventional phenotypic features, growth responses to $\mathrm{pH}, \mathrm{NaCl}$ concentration in the cultivation medium and temperature, analysis of fermentation products, chemotaxonomic analysis, determination of DNA G $+\mathrm{C}$ content and DNA-DNA relatedness and phylogenetic analysis were as described previously (Ishikawa et al., 2003, 2005), except as noted below.

Flagellation was observed for cells grown on $75 \%$ seawaterbased Bacto tryptic soy agar (Difco) supplemented with $0.1 \%(\mathrm{w} / \mathrm{v})$ glucose $(\mathrm{pH} 9.0)$ at $25{ }^{\circ} \mathrm{C}$ anaerobically for 1 day. Antibiotic sensitivity was investigated by placing a filter-paper disc impregnated with antibiotic onto plates of $2.5 \% \mathrm{NaCl}$ GYPF agar. To investigate the effect of the initial $\mathrm{pH}$ of the anaerobic cultivation medium on the composition of the glucose-fermentation products, cultivation was performed in $2.5 \% \mathrm{NaCl}$ GYPF broth $(1 \%$ glucose), which was buffered by adding $100 \mathrm{mM}$ Good's buffers: HEPES at pH 7.0 and CHES at pH 8.0 and 9.0. The composition of cellular fatty acids of representative strains $\left(\mathrm{T} 117-1-2^{\mathrm{T}}, \mathrm{T} 143-1-1^{\mathrm{T}}, \mathrm{T} 129-2-1^{\mathrm{T}}\right.$ and $\mathrm{T} 22-1-2^{\mathrm{T}}$ ) and reference strains (A. iburiense JCM $12662^{\mathrm{T}}, M$. psychrotolerans $\mathrm{M} 13-2^{\mathrm{T}}$ and $M$. piezotolerans JCM $12337^{\mathrm{T}}$ ) was analysed by using the Sherlock Microbial Identification system (version 5.0; MIDI) with a gas chromatograph (model HP6890; Hewlett Packard). Fatty acid methyl esters were prepared according to the 
Table 1. List of isolates and their sources, sites and dates of isolation

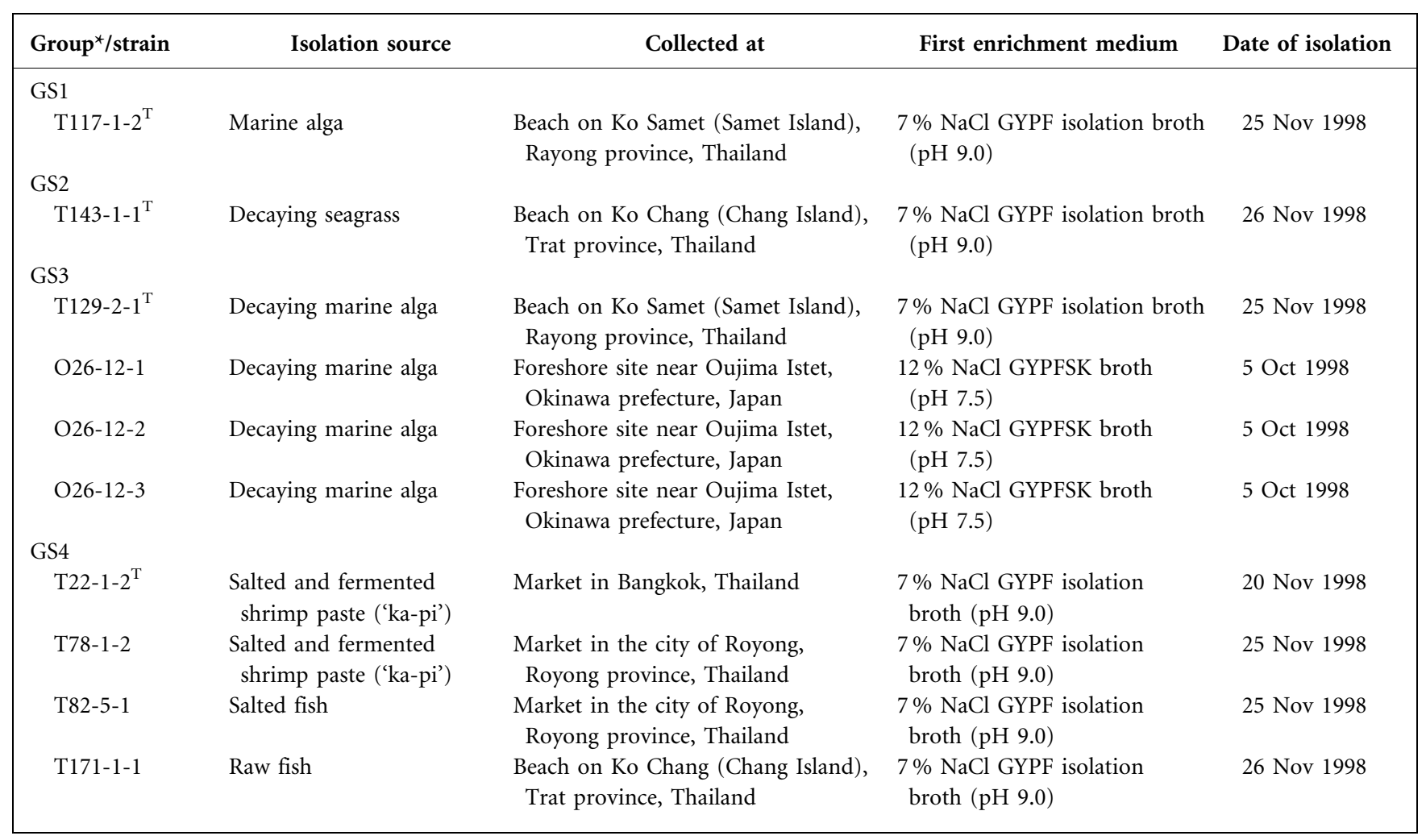

${ }^{\star}$ Based on the results of DNA-DNA relatedness.

manufacturer's instructions for the MIDI system. All of the tested strains were cultivated by using $2.5 \% \mathrm{NaCl}$ GYPF broth ( $\mathrm{pH} 9.0$ ) in standing culture for 1 day.

All 10 new isolates exhibited similar phenotypic features. Cells were Gram-positive and rod-shaped. They were motile with peritrichous flagella, except for strains T117$1-2^{\mathrm{T}}$ and $\mathrm{T} 22-1-2^{\mathrm{T}}$ (Fig. 1). They did not produce spores or catalase. Cultural characteristics, cellular morphology, sensitivity to antibiotics and other conventional taxonomic features are given in the descriptions of the novel species.

The 10 isolates all required carbohydrates or related compounds for growth under aerobic, as well as anaerobic, conditions. Whilst the $\mathrm{OD}_{660}$ of cultures grown aerobically in $2.5 \% \mathrm{NaCl}$ GCY broth ( $1 \%$ glucose) was $0.3-0.9$, that of cultures grown in $2.5 \% \mathrm{NaCl}$ GCY broth from which glucose was omitted was $<0.1$. Similarly, growth was poor in $2.5 \% \mathrm{NaCl}$ GYPF broth in which the glucose concentration was reduced from 1.0 to $0.1 \%$, and did not occur when glucose was omitted from the broth.

The 10 isolates were aerotolerant. When semi-solid $2.5 \%$ $\mathrm{NaCl}$ GYPF medium $(0.15 \%$ agar $)$ in a test tube was inoculated with a small amount of broth culture, mixed and incubated statically, the colonies that developed were uniform in both density and size throughout the medium column (about $6 \mathrm{~cm}$ in height). When cultivated on an agar plate exposed to the atmosphere, the growth was less vigorous than that on an agar plate incubated anaerobically.

Nearly complete sequences of the 16S rRNA genes of the isolates were compared with those of lactic acid bacteria and other related bacteria from public databases. In the phylogenetic tree, the 10 isolates comprised three phylogenetic clusters within the radiation of the described and phylogenetically assigned species of the genus Alkalibacterium (Fig. 2; Supplementary Fig. S1, available in IJSEM Online).

DNA-DNA hybridization experiments showed that these 10 isolates constitute four genomic species. The DNADNA relatedness values among the isolates and type strains of phylogenetically related taxa are shown in Supplementary Table S1, available in IJSEM Online. No significant DNA-DNA relatedness was obtained between strains T117-1-2 ${ }^{\mathrm{T}}, \mathrm{T} 143-1-1^{\mathrm{T}}$ and A. indicireducens JCM $14232^{\mathrm{T}}$, which were constituents of the same phylogenetic cluster (Fig. 2; Supplementary Fig. S1). Each of the other two phylogenetic clusters comprised a single genomic species. These four genomic species are designated groups GS1 (for T117-1-2 ${ }^{\mathrm{T}}$ ), GS2 (for T143-1-1 ${ }^{\mathrm{T}}$ ), GS3 (for T1292-1 ${ }^{\mathrm{T}}$, O26-12-1, O26-12-2 and O26-12-3) and GS4 (for T22-1-2 ${ }^{\mathrm{T}}$, T78-1-2, T82-5-1 and T171-1-1). The G+C contents of the DNA of the isolates fell within the range 

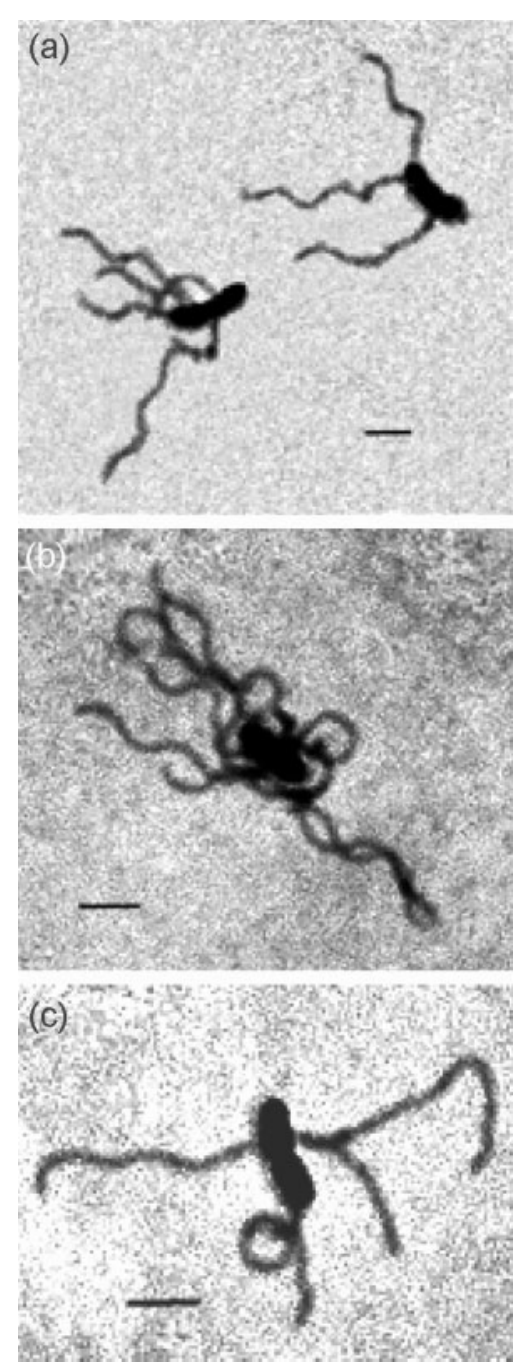

Fig. 1. Photomicrographs of a cell and peritrichous flagella of $A$. pelagium T143-1-1 ${ }^{\top}$ (a), A. putridalgicola T129-2-1 ${ }^{\top}$ (b) and $A$. kapii T78-1-2 (c) grown anaerobically at $25{ }^{\circ} \mathrm{C}$ for 1 day on $75 \%$ seawater-based Bacto tryptic soy agar supplemented with $0.1 \%$ (w/v) glucose ( $\mathrm{pH}$ 9.0). Bars, $2 \mu \mathrm{m}$.

38.4-42.7 mol\%; the values for each genomic species are shown in Supplementary Table S1. Levels of DNA-DNA relatedness among the type strains of the four genomic species and those of species of the genera Alkalibacterium and Marinilactibacillus were 3-46\% - as low as levels between distinct species (Supplementary Table S1).

16S rRNA gene sequence similarity values among the isolates and members of the genera Alkalibacterium and Marinilactibacillus are given in Supplementary Table S2, with the GenBank accession numbers of the isolates. Similarity between the four genomic species was 97.1$99.7 \%$. The similarity between groups GS1 and GS2 was $99.7 \%$. Groups GS1 and GS2 showed the highest similarity (99.7 and $99.8 \%$, respectively) to A. indicireducens $\mathrm{A} 11^{\mathrm{T}}$, which was isolated from polygonum indigo fermentation liquor (Yumoto et al., 2008). The 16S rRNA gene sequences of isolates belonging to group GS3 were identical to each other and to that of Alkalibacterium sp. ARD M22. Their sequences were also $99.2 \%$ similar to that of Alkalibacterium sp. ARD M12. These two uncharacterized strains (ARD M12 and ARD M22) were isolated from deep seawater (only the 16S rRNA gene sequences are available; GenBank accession nos AB167070 and AB167074, respectively). The members of group GS4 exhibited 98.1-98.2\% $16 \mathrm{~S}$ rRNA gene sequence similarity between them and 98.0-98.2\% similarity to the members of group GS3 and Alkalibacterium sp. ARD M22. All of the four genomic species were related most closely to A. indicireducens among the four described species of the genus Alkalibacterium. The similarity values between $A$. indicireducens and each of the genomic species were $99.7 \%$ (group GS1), 99.8\% (group GS2), 98.1-98.2\% (group GS3) and 97.1-97.2\% (group GS4).

The fermentation profiles of carbohydrates, sugar alcohols and related carbon compounds of the isolates are given in Table 2. The isolates utilized a fairly wide range of substrates, except for group GS4, which exhibited a rather limited utilization profile. All of the isolates utilized gluconate without gas production, and starch.

The isolates were slightly halophilic (Kushner, 1978; Kushner \& Kamekura, 1988) and halotolerant. The optimum $\mathrm{NaCl}$ concentrations for growth were between 1.0 and $2.5 \%$ for group GS1 $\left(\mathrm{T} 117-1-2^{\mathrm{T}}\right)$, between 0.5 and $1.5 \%$ for group GS2 (T143-1-1 ${ }^{\mathrm{T}}$ ), between 2.0 and $4.0 \%$ for group GS3 and between 1.5 and $2.5 \%$ for group GS4. The maximum specific growth rates of the type strains of the genomic species at each of the different $\mathrm{NaCl}$ concentrations tested are described in Supplementary Table S3, available in IJSEM Online. Strain T117-1-2 (group GS1) was able to grow between $0 \%$ (weak) and $11.0 \% \mathrm{NaCl}$, strain $\mathrm{T} 143-1-1^{\mathrm{T}}$ between 0 and $17 \%$, members of group GS3 between $0 \%$ (weak) and 18.0$20.0 \%$ and those of group GS4 between 0 and 19-21\% $\mathrm{NaCl}$.

The isolates were alkaliphiles according to the note of Jones et al. (1994): alkaliphiles are organisms that grow optimally at $\mathrm{pH}$ values $>8$. The optimum $\mathrm{pH}$ for growth was 9.0 for the single member of group GS1, between 9.0 and 9.5 for that of group GS2, between 8.0 and 9.0 for members of group GS3 and between 8.5 and 9.0 for those of group GS4. No growth was observed in media for which the initial $\mathrm{pH}$ was $\leqslant 6.5$ or $\geqslant 11.5$ for the single members of groups GS1 and GS2, $\leqslant 6.0\left(\leqslant 5.5\right.$ for T129-2-1 $\left.1^{\mathrm{T}}\right)$ or $\geqslant 10.5$ for the members of group GS3 and $\leqslant 5.5-6.0$ or $\geqslant 10.5$ for those of group GS4. The maximum specific growth rates of the type strains of the genomic species are described in Supplementary Table S3.

M. psychrotolerans, Halolactibacillus halophilus and Halolactibacillus miurensis were isolated from marine organisms (decaying marine algae, a live sponge and a fresh shellfish, respectively) and are marine-inhabiting 


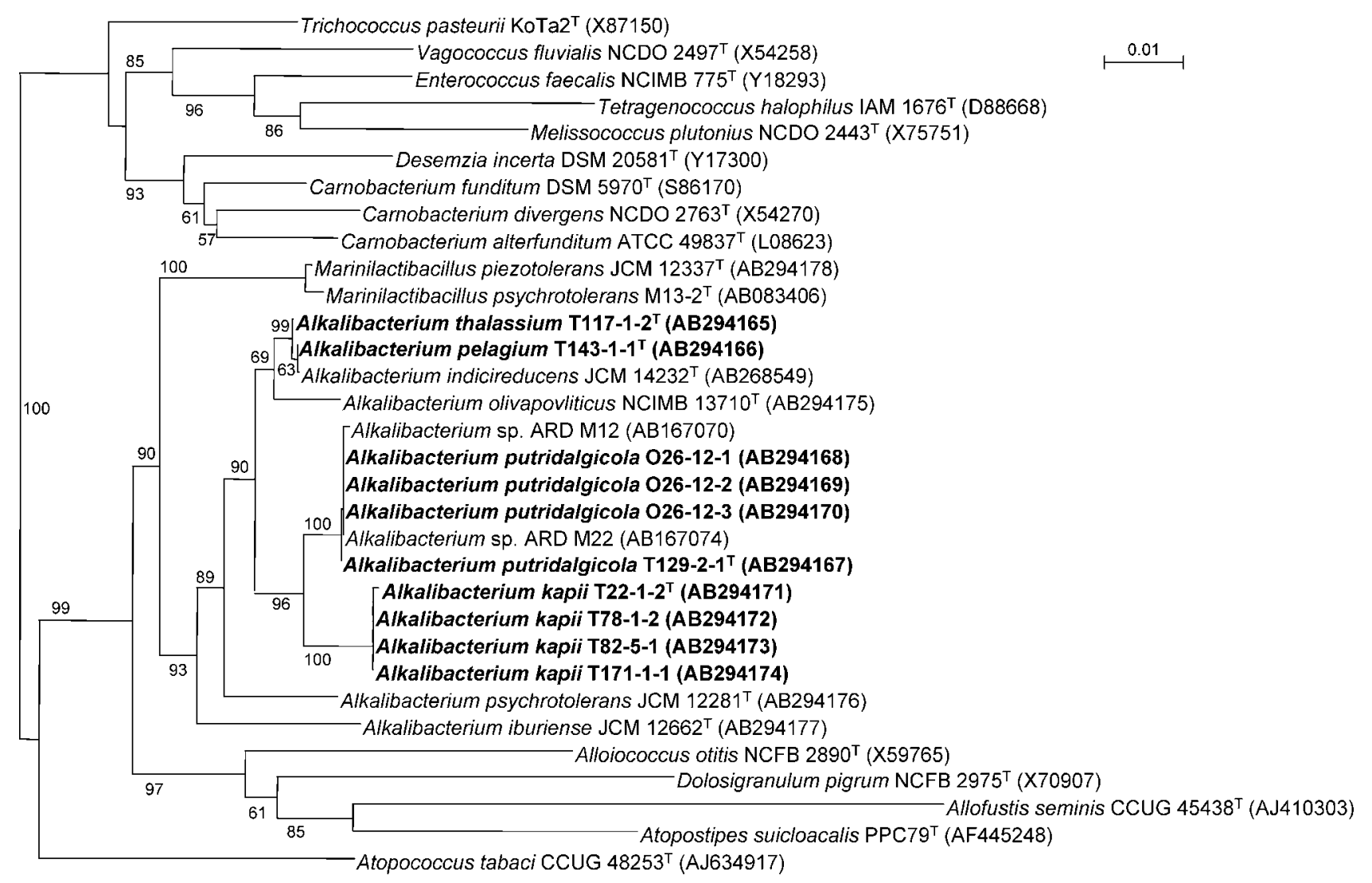

Fig. 2. Phylogenetic relationships among the 10 new isolates and related bacteria. The tree, constructed by the neighbourjoining method, is based on a comparison of approximately $1400 \mathrm{nt}$. Bootstrap values, expressed as a percentage of 1000 replications, are given at branching points; only values $>50 \%$ are shown. Bar, $0.01 K_{\text {nuc. }}$.

lactic acid bacteria with growth optima at $2.00-3.75 \%$ $\mathrm{NaCl}$ and $\mathrm{pH} 8.5-9.0$, consistent with the physicochemical conditions of seawater (Ishikawa et al., 2003, 2005). For these organisms, we previously proposed the term 'marine lactic acid bacteria' (Ishikawa et al., 2003). As described later, the 10 present isolates are also lactic acid bacteria, producing lactic acid as the main product of glucose fermentation. Further, the isolates were marine inhabitants, isolated from marine organisms or salted foods produced from marine organisms and had halophilic and alkaliphilic properties consistent with those of seawater. These new isolates can be regarded as additional representatives of marine lactic acid bacteria within the phylogenetic radiation of typical lactic acid bacteria. Recently, new members of the genus Alkalibacterium have been isolated from other marine environments: Alkalibacterium spp. ARD M12 and ARD M22 from deep seawater potentially affected by a hydrothermal plume, Knipovich Ridge, Arctic Ocean (only the 16S rRNA gene sequences are available).

The optimum growth temperatures of the isolates were $37{ }^{\circ} \mathrm{C}$ (groups GS1 and GS2), $37-40{ }^{\circ} \mathrm{C}$ (group GS3) and $25-37{ }^{\circ} \mathrm{C}$ (group GS4). The maximum specific growth rates of the type strains of the four genomic species at 25.0-
$42.5{ }^{\circ} \mathrm{C}$, near their temperature optima, are shown in Supplementary Table S3. The ranges of temperature for growth were $10.0-42.5{ }^{\circ} \mathrm{C}$ (group GS1), $10.0-47.5{ }^{\circ} \mathrm{C}$ (group GS2), -1.8 to $40-45{ }^{\circ} \mathrm{C}$ (group GS3) and 5-10 to $40.0-42.5{ }^{\circ} \mathrm{C}$ (group GS4). The members of group GS3 grew well at lower temperatures, in terms of maximum growth attained, as did M. psychrotolerans (Ishikawa et al., 2003), although growth rates were low. $\mathrm{OD}_{660}$ values at $-1.8{ }^{\circ} \mathrm{C}$ were $0.4-0.5$ (20 days) and those at $30-37{ }^{\circ} \mathrm{C}$ (i.e. optimum temperature) were 1.0-1.2 (20-24 h).

Fermentation products from glucose were analysed for anaerobic cultures grown in $2.5 \% \mathrm{NaCl}$ GYPF broth. Lactate, formate, acetate and ethanol were produced without generation of gas. The yield of lactate per glucose molecule consumed was $64-93 \%$, depending on the isolate. The relative amounts of formate, acetate and ethanol (molar ratio) were approximately $2: 1: 1$. The major optical isomer of lactate was the L-type for groups GS2, GS3 and GS4, with a relative ratio of $59-82 \%$ of the total lactate produced, whereas group GS1 produced solely D-lactate. The effect of the initial $\mathrm{pH}$ of the fermentation medium on the yield of lactate produced (mol glucose consumed $)^{-1}$ was investigated by using buffered medium 
Table 2. Profiles of sugar fermentation of the 10 new isolates

All 10 strains fermented D-ribose, D-glucose, D-fructose, D-mannose, maltose, sucrose, trehalose, starch and sodium gluconate and did not ferment L-rhamnose, melibiose, adonitol, myo-inositol or dulcitol. Fermentation was scored as positive $(+)$ when the titre of $0.1 \mathrm{M} \mathrm{NaOH}$ per $5 \mathrm{ml}$ culture broth was $\geqslant 0.7 \mathrm{ml}$, as weakly positive $(\mathrm{w})$ when the titre was $\geqslant 0.5 \mathrm{ml}$ and $<0.7 \mathrm{ml}$, and as negative $(-)$ for titres $<0.5 \mathrm{ml}$.

\begin{tabular}{|c|c|c|c|c|c|c|c|c|c|c|}
\hline \multirow{3}{*}{$\begin{array}{l}\text { Carbon } \\
\text { compound }\end{array}$} & \multicolumn{10}{|c|}{ Group/strain } \\
\hline & \multirow{2}{*}{$\frac{\mathrm{GS} 1}{\mathrm{~T} 117-1-2^{\mathrm{T}}}$} & \multirow{2}{*}{$\frac{\text { GS2 }}{\text { T143-1-1 }}$} & \multicolumn{4}{|c|}{ GS3 } & \multicolumn{4}{|c|}{ GS4 } \\
\hline & & & T129-2-1 ${ }^{\mathrm{T}}$ & O26-12-1 & O26-12-2 & 026-12-3 & $\mathrm{T} 22-1-2^{\mathrm{T}}$ & T78-1-2 & T82-5-1 & T171-1-1 \\
\hline L-Arabinose & - & + & + & + & + & + & - & - & - & - \\
\hline D-Arabinose & - & - & - & - & - & - & - & - & - & + \\
\hline D-Xylose & - & + & + & + & + & + & - & - & - & - \\
\hline D-Galactose & + & + & + & - & - & - & - & - & - & - \\
\hline Cellobiose & + & + & + & + & + & + & - & + & + & + \\
\hline Lactose & $\mathrm{w}$ & + & $\mathrm{W}$ & + & + & + & - & - & - & - \\
\hline Raffinose & $\mathrm{W}$ & $\mathrm{W}$ & + & + & + & + & - & - & - & - \\
\hline D-Salicin & + & + & + & + & + & + & - & - & - & - \\
\hline Melezitose & - & - & - & + & + & + & - & - & - & - \\
\hline D-Mannitol & - & - & - & + & + & + & - & - & - & - \\
\hline D-Sorbitol & - & - & - & + & + & + & + & - & - & - \\
\hline $\begin{array}{l}\alpha \text {-Methyl-D- } \\
\text { glucoside }\end{array}$ & - & - & - & - & + & + & - & - & - & - \\
\hline Glycerol & $\mathrm{W}$ & - & - & + & $\mathrm{W}$ & + & - & - & + & $\mathrm{W}$ \\
\hline Inulin & - & - & + & - & + & + & - & - & - & - \\
\hline
\end{tabular}

for the representative strains T117-1-2 ${ }^{\mathrm{T}}$ (group GS1), T143-1-1 ${ }^{\mathrm{T}}$ (group GS2), T129-2-1 ${ }^{\mathrm{T}}$ (group GS3) and T22$1-2^{\mathrm{T}}$ (group GS4). To minimize the effect of a $\mathrm{pH}$ change that might occur during cultivation, product analysis was performed when cultures were at an early stage of growth (i.e. $\mathrm{OD}_{660}$ of approx. 0.2). The initial $\mathrm{pH}$ markedly affected the yield of lactate (Table 3 ). As the initial acidity increased, the yield of lactate from glucose increased; in the case of T143-1-1 ${ }^{\mathrm{T}}$ (group GS2), the yield of $48 \%$ at $\mathrm{pH} 9$ increased to $87 \%$ at $\mathrm{pH} 7$, whereas the yields of the other three products decreased, retaining the relative molar ratio among them. Except for M. piezotolerans (which produced similar amounts of lactic acid regardless of $\mathrm{pH}$ ), the reference strains (type strains of $M$. psychrotolerans, A. olivapovliticus, A. psychrotolerans and A. iburiense) exhibited essentially the same inverse relationship of lactate yield with regard to the initial $\mathrm{pH}$ value of the medium. As has been discussed for the lactic acid bacteria Marinilactibacillus and Halolactibacillus and for A. olivapovliticus (Ishikawa et al., 2003, 2005), we deduced that the new isolates and described species of the genus Alkalibacterium possessed the Embden-Meyerhof pathway and the pyruvate-associated enzymes lactate dehydrogenase and pyruvate-formate lyase, whose relative activities were affected by the $\mathrm{pH}$ value of the fermentation medium. Several homofermentative lactic acid bacteria produce formate, acetate and ethanol in a relative molar ratio of $2: 1: 1$ with production of lactate from glucose fermentation; these organisms also showed decreased production of lactate, while inversely increasing production of the other three products, in media with alkaline $\mathrm{pH}$ or limited glucose (Gunsalus \& Niven, 1942; Carlsson \& Griffith, 1974; Rhee \& Park, 1980). These cultivation conditions are considered to affect the relative activities of lactate dehydrogenase and pyruvate-formate lyase, thereby altering the balance between lactate and other products (Carlsson \& Griffith, 1974; Yamada \& Carlsson, 1975; Axelsson, 1993).

The 10 new isolates grew aerobically, although they lack catalase and respiratory quinones (see later section). The type strains of each genomic species, T117-1-2 ${ }^{\mathrm{T}}$ (group GS1), T143-1-1 ${ }^{\mathrm{T}}$ (group GS2), T129-2-1 ${ }^{\mathrm{T}}$ (group GS3) and $\mathrm{T} 22-1-2^{\mathrm{T}}$ (group GS4), produced acetate and lactate from glucose under aerobic conditions, but did not generate formate or ethanol. The type strains of A. olivapovliticus, $A$. psychrotolerans, $A$. iburiense and $M$. psychrotolerans behaved similarly under these conditions; $M$. piezotolerans JCM $12337^{\mathrm{T}}$ produced only acetate (Table 4).

The behaviour of the isolates under aerobic conditions described above is similar to that of Amphibacillus xylanus (Niimura et al., 1990). Amphibacillus xylanus produces formate, acetate and ethanol with a molar ratio of $2: 1: 1$ from pyruvate generated through the Embden-Meyerhof pathway under anaerobic conditions. Although lacking catalase, cytochromes and quinones and possessing an anaerobic pathway, Amphibacillus xylanus has an aerobic pathway that is not mediated by the respiratory chain, 
Table 3. Effect of initial $\mathrm{pH}$ of culture medium on the product balance of glucose fermentation by the type strains of each genomic species and phylogenetically related species

\begin{tabular}{|c|c|c|c|c|c|c|c|}
\hline Strain & Initial pH & \multicolumn{4}{|c|}{ End products [mol (mol glucose $\left.)^{-1}\right]$} & $\begin{array}{l}\text { Lactate yield } \\
\text { from consumed } \\
\text { glucose }(\%)\end{array}$ & $\begin{array}{c}\text { Carbon } \\
\text { recovery } \\
(\%)\end{array}$ \\
\hline \multirow[t]{2}{*}{ T117-1-2 (group GS1) } & 7 & 1.06 & 0.69 & 0.50 & 0.54 & 53 & 99 \\
\hline & 8 & 0.81 & 0.98 & 0.59 & 0.52 & 40 & 93 \\
\hline \multirow{2}{*}{ T143-1-1 ${ }^{\mathrm{T}}$ (group GS2) } & 8 & 1.20 & 0.99 & 0.44 & 0.29 & 60 & 101 \\
\hline & 9 & 0.95 & 0.77 & 0.43 & 0.50 & 48 & 92 \\
\hline \multirow[t]{3}{*}{ T129-2-1 ${ }^{\mathrm{T}}$ (group GS3) } & 7 & 1.77 & 0.27 & 0.10 & 0.06 & 88 & 98 \\
\hline & 8 & 1.03 & 1.45 & 0.69 & 0.43 & 51 & 112 \\
\hline & 9 & 0.96 & 1.56 & 0.77 & 0.40 & 48 & 113 \\
\hline $\mathrm{T} 22-1-2^{\mathrm{T}}$ (group GS4) & 7 & 1.76 & 0.32 & 0.14 & 0.11 & 88 & 101 \\
\hline \multirow{2}{*}{ A. olivapovliticus NCIMB $13710^{T_{\star}}$} & 9 & 1.01 & 1.21 & 0.53 & 0.52 & 50 & 106 \\
\hline & 10 & 0.78 & 1.49 & 0.65 & 0.75 & 39 & 111 \\
\hline \multirow[t]{3}{*}{ A. psychrotolerans JCM $12281^{\mathrm{T}}$} & 8 & 0.82 & 1.21 & 0.63 & 0.49 & 41 & 98 \\
\hline & 9 & 0.51 & 1.20 & 0.62 & 0.78 & 25 & 92 \\
\hline & 10 & 0.30 & 1.74 & 1.13 & 0.77 & 15 & 108 \\
\hline \multirow[t]{3}{*}{ A. iburiense JCM $12662^{\mathrm{T}}$} & 8 & 0.54 & 1.63 & 5.57 & 7.98 & 27 & 109 \\
\hline & 9 & 0.52 & 1.46 & 0.67 & 0.79 & 26 & 98 \\
\hline & 10 & 0.20 & 2.43 & 0.61 & 0.90 & 10 & 100 \\
\hline \multirow[t]{3}{*}{ M. psychrotolerans $\mathrm{M} 13-2^{\mathrm{T}_{\star}}$} & 7 & 2.02 & 0.15 & 0.04 & 0.05 & 101 & 107 \\
\hline & 8 & 1.50 & 0.52 & 0.20 & 0.19 & 75 & 97 \\
\hline & 9 & 1.29 & 0.81 & 0.35 & 0.20 & 66 & 98 \\
\hline M. piezotolerans JCM $12337^{\mathrm{T}}$ & 7 & 1.07 & 0.72 & 0.43 & 0.39 & 54 & 93 \\
\hline
\end{tabular}

${ }^{\star}$ Data from Ishikawa et al. (2003).

producing only acetate and $\mathrm{CO}_{2}$ from glucose (Niimura et al., 1989). Oxidative pathways similar to that of Amphibacillus xylanus have been reported for several other lactic acid bacteria, including Streptococcus mutans, Lactobacillus spp., Streptococcus spp., Leuconostoc spp., Trichococcus flocculiformis, $M$. psychrotolerans, H. halophilus and H. miurensis (Fukui et al., 1988; Sakamoto \& Komagata, 1996; Liu et al., 2002; Ishikawa et al., 2005). As these reports suggest, the four genomic species described here, as well as A. olivapovliticus, A. psychrotolerans, A. iburiense and $M$. piezotolerans, probably have a system for aerobic metabolism of glucose similar to that present in Amphibacillus xylanus, M. psychrotolerans, Halolactibacillus spp. and other lactic acid bacteria.

meso-Diaminopimelic acid was not associated with the cellwall peptidoglycans of the new isolates as determined by TLC. The purified cell walls of strains T117-1-2 ${ }^{\mathrm{T}}$ (group GS1), T143-1-1 ${ }^{\mathrm{T}}$ (group GS2) and T129-2-1 ${ }^{\mathrm{T}}$ (group GS3) contained aspartic acid, glutamic acid, alanine and ornithine in a molar ratio of $0.43-0.54: 1: 1.9-2.3: 0.95-$
0.98. In comparison, strain $\mathrm{T} 22-1-2^{\mathrm{T}}$ (group GS4) contained glutamic acid, alanine and ornithine in a molar ratio of $1: 1.2: 0.7$. From these results, It was inferred that strains T117-1-2 ${ }^{\mathrm{T}}$ (group GS1), T143-1-1 ${ }^{\mathrm{T}}$ (group GS2) and T129-2-1 ${ }^{\mathrm{T}}$ (group GS3) contained peptidoglycan type A $4 \beta$, Orn-D-Asp, which is the cell-wall type of $A$. olivapovliticus (Ishikawa et al., 2003) and differs from those of A. psychrotolerans and A. indicireducens [type A4 $\alpha$, Lys (Orn)-D-Asp] (Nakajima et al., 2005; Yumoto et al., 2008) and A. iburiense (type A $4 \alpha$, Lys-D-Asp) (Yumoto et al., 2004). Strain T22-1-2 ${ }^{\mathrm{T}}$ (group GS4) had peptidoglycan type A $4 \beta$, Orn-D-Glu, which is the cell-wall type of $M$. psychrotolerans (Ishikawa et al., 2003) and differs from those of the other three genomic species and the four described species of the genus Alkalibacterium. Thus, the genus Alkalibacterium comprises three types of species with regard to cell-wall type of peptidoglycan.

The major cellular fatty acids of strains T117-1-2 ${ }^{\mathrm{T}}$ (group GS1), T143-1-1 ${ }^{\mathrm{T}}$ (group GS2), T129-2-1 ${ }^{\mathrm{T}}$ (group GS3) and T22-1-2 ${ }^{\mathrm{T}}$ (group GS4) were straight-chain saturated and 
Table 4. Products from glucose under aerobic cultivation of the type strains of each genomic species and phylogenetically related species

Formate and ethanol were not detected (ND) for any of the strains.

\begin{tabular}{|c|c|c|c|c|}
\hline \multirow[t]{2}{*}{ Strain } & \multirow{2}{*}{$\begin{array}{c}\text { Glucose } \\
\text { consumed }(\mathrm{mM})\end{array}$} & \multicolumn{2}{|c|}{ Products $(\mathrm{mM})$} & \multirow{2}{*}{$\begin{array}{c}\text { Carbon } \\
\text { recovery }(\%)^{\star}\end{array}$} \\
\hline & & Lactate & Acetate & \\
\hline T117-1-2 ${ }^{\mathrm{T}}$ (group GS1) & 12.6 & 9.8 & 16.5 & 104 \\
\hline T143-1-1 ${ }^{\mathrm{T}}$ (group GS2) & 15.4 & 9.1 & 19.7 & 93 \\
\hline T129-2-1 ${ }^{\mathrm{T}}$ (group GS3) & 21.6 & 35.7 & 8.5 & 102 \\
\hline T22-1-2 ${ }^{\mathrm{T}}$ (group GS4) & 13.6 & 17.0 & 12.9 & 110 \\
\hline A. olivapovliticus NCIMB $13710^{\mathrm{T}}$ & 15.5 & 14.4 & 18.2 & 105 \\
\hline A. psychrotolerans JCM $12281^{\mathrm{T}}$ & 15.0 & 16.1 & 15.1 & 104 \\
\hline A. iburiense JCM $12662^{\mathrm{T}}$ & 22.1 & 17.7 & 25.3 & 97 \\
\hline M. psychrotolerans $\mathrm{M} 13-2^{\mathrm{T}} \dagger$ & 33.2 & 21.5 & 40.0 & 93 \\
\hline M. piezotolerans JCM $12337^{\mathrm{T}}$ & 7.8 & $\mathrm{ND}$ & 15.7 & 101 \\
\hline
\end{tabular}

${ }^{\star}$ Carbon recovery was calculated on the assumption that acetate and $\mathrm{CO}_{2}$ were produced in equimolar amounts.

$\dagger$ Data from Ishikawa et al. (2005)

monounsaturated, even-carbon-numbered types (Supplementary Table S4, available in IJSEM Online), primarily $\mathrm{C}_{16: 0}, \mathrm{C}_{16: 1} \omega 9 c$ and $\mathrm{C}_{18: 1} \omega 9 c$ (oleic acid).

Respiratory quinones were not present in strains T117-1-2 ${ }^{\mathrm{T}}$ (group GS1), T143-1-1 ${ }^{\mathrm{T}}$ (group GS2), T129-2-1 ${ }^{\mathrm{T}}$ (group GS3) or T22-1-2 (group GS4).

All four genomic species were similar to those of the genera Alkalibacterium and Marinilactibacillus in the following characteristics: cellular morphology, various biochemical features, halophilic/halotolerant and alkaliphilic/alkalitolerant properties, products from glucose under aerobic and anaerobic conditions, effect of $\mathrm{pH}$ of medium on fermentation products and the $\mathrm{G}+\mathrm{C}$ content of the DNA. Although sharing important taxonomic features, the four novel genomic species, the four described species of the genus Alkalibacterium and the two described species of the sister genus Marinilactibacillus can be distinguished from each other by a combination of features of the sugarfermentation pattern, sensitivity to antibiotics, growth responses to $\mathrm{NaCl}$ concentration, $\mathrm{pH}$ and temperature, ability to produce ammonia from arginine, peptidoglycan type and $\mathrm{G}+\mathrm{C}$ content of the DNA (Table 5).

Phylogenetically, the described four species of the genus Alkalibacterium and the four genomic species described in the present study compose an independent cluster separate from the cluster of the genus Marinilactibacillus in phylogenetic trees reconstructed by both the neighbourjoining and the maximum-likelihood methods (Fig. 2; Supplementary Fig. S1, available in IJSEM Online).

In conclusion, on the basis of the phenotypic features and phylogenetic and genetic independence that we have described, the isolates should be classified as belonging to four novel species of the genus Alkalibacterium. We propose the names Alkalibacterium thalassium sp. nov. for group GS1, Alkalibacterium pelagium sp. nov. for group GS2, Alkalibacterium putridalgicola sp. nov. for group GS3 and Alkalibacterium kapii sp. nov. for group GS4.

\section{Description of Alkalibacterium thalassium sp. nov.}

Alkalibacterium thalassium [tha.las'si.um. N.L. neut. adj. thalassium (from Gr. adj. thalassios - a -on) of/from the sea].

Cells are Gram-positive, non-sporulating, non-motile, straight rods measuring $0.6-1.4 \times 3.6-9.0 \mu \mathrm{m}$, occurring singly, in pairs or in short chains. Deep colonies in $2.5 \%$ $\mathrm{NaCl}$ GYPF agar medium are pale yellow, opaque and lenticular, with diameters of $1.0-2.0 \mathrm{~mm}$ after 3 days at $30{ }^{\circ} \mathrm{C}$. Surface colonies are round, convex, entire, pale yellow and transparent, with diameters of 0.5-1.0 $\mathrm{mm}$ after 3 days at $30{ }^{\circ} \mathrm{C}$. Aerotolerant. Grows evenly throughout a column of semi-solid agar medium. Catalase- and oxidasenegative. Quinones are not detected. Negative for nitrate reduction, gelatin liquefaction and production of ammonia from L-arginine. Slightly halophilic; the optimum $\mathrm{NaCl}$ concentration for growth is $1.0-2.5 \%(\mathrm{w} / \mathrm{v})$, with a range of $0.0-11.0 \%(\mathrm{w} / \mathrm{v})$. Alkaliphilic; the optimum $\mathrm{pH}$ for growth is 9.0, with a range of 7.0-11.0. Growth occurs between 10 and $42.5^{\circ} \mathrm{C}$, with an optimum temperature of $37{ }^{\circ} \mathrm{C}$. Lactic acid is the major fermentation product from D-glucose; other products are formate, acetate and ethanol with a molar ratio of approximately $2: 1: 1$, without gas formation. Lactate yield decreases at higher $\mathrm{pH}$ of the fermentation medium (analysed for the type strain). DGlucose is metabolized aerobically to acetate in addition to lactate (analysed for the type strain). The fermentation profile of carbohydrates, sugar alcohols and related carbon compounds is given in Table 2. Not inhibited by chloramphenicol, kanamycin or trimethoprim; inhibited by ampicillin. The peptidoglycan is A $4 \beta$, Orn-D-Asp type. The major cellular fatty acids are $\mathrm{C}_{16: 0}, \mathrm{C}_{16: 1} \omega 9 c$ and 
$\mathrm{C}_{18: 1} \omega 9 c$ (oleic acid). The $\mathrm{G}+\mathrm{C}$ content of the DNA of strain $\mathrm{T} 117-1-2^{\mathrm{T}}$ is $41.7 \mathrm{~mol} \%$.

The type strain is T117-1-2 $2^{\mathrm{T}}\left(=\mathrm{DSM} \quad 19181^{\mathrm{T}}=\mathrm{NBRC}\right.$ $103241^{\mathrm{T}}=$ NRIC $0718^{\mathrm{T}}$ ), which was isolated from a decaying marine alga collected at the seashore of Ko Samet (Samet Island), Rayong province, Thailand.

\section{Description of Alkalibacterium pelagium sp. nov.}

Alkalibacterium pelagium (pe.la'gi.um. N.L. neut. adj. pelagium of the sea, marine).

Cells are Gram-positive, non-sporulating, straight rods measuring $0.3-0.9 \times 1.8-7.2 \mu \mathrm{m}$, occurring singly, in pairs or in short chains. Motile with peritrichous flagella. Deep colonies in $2.5 \% \mathrm{NaCl}$ GYPF agar medium are pale yellow, opaque and lenticular, with diameters of 1.0-2.0 mm after 3 days at $30{ }^{\circ} \mathrm{C}$. Surface colonies are round, convex, entire, pale yellow and transparent, with diameters of $0.5-1.0 \mathrm{~mm}$ after 3 days at $30{ }^{\circ} \mathrm{C}$. Aerotolerant. Grows evenly throughout a column of semi-solid agar medium. Catalase- and oxidase-negative. Quinones are not detected. Negative for nitrate reduction, gelatin liquefaction and production of ammonia from L-arginine. Slightly halophilic and highly halotolerant; the optimum $\mathrm{NaCl}$ concentration for growth is $0.5-1.5 \%(\mathrm{w} / \mathrm{v})$ with a range of $0.0-17.0 \%(\mathrm{w} / \mathrm{v})$. Alkaliphilic; the optimum $\mathrm{pH}$ for growth is $9.0-9.5$, with a range of 7.0-11.0. Growth occurs between 10 and $47.5{ }^{\circ} \mathrm{C}$, with an optimum temperature of $37^{\circ} \mathrm{C}$. Lactic acid is the major fermentation product from $\mathrm{D}$-glucose; other products are formate, acetate and ethanol with a molar ratio of approximately $2: 1: 1$, without gas formation. Lactate yield decreases at higher $\mathrm{pH}$ of the fermentation medium (analysed for the type strain). D-Glucose is metabolized aerobically to acetate in addition to lactate (analysed for the type strain). The fermentation profile of carbohydrates, sugar alcohols and related carbon compounds is given in Table 2. Not inhibited by chloramphenicol or kanamycin; inhibited by ampicillin and trimethoprim. The peptidoglycan is A4 $\beta$, Orn-D-Asp type. The major cellular fatty acids are $\mathrm{C}_{16: 0}, \mathrm{C}_{16: 1} \omega 9 c$ and $\mathrm{C}_{18: 1} \omega 9 c$ (oleic acid). The $\mathrm{G}+\mathrm{C}$ content of the DNA of strain T143-1-1 ${ }^{\mathrm{T}}$ is $42.2 \mathrm{~mol} \%$.

The type strain is T143-1-1 ${ }^{\mathrm{T}}\left(=\mathrm{DSM} 19183^{\mathrm{T}}=\mathrm{NBRC}\right.$ $103242^{\mathrm{T}}=$ NRIC $0719^{\mathrm{T}}$ ), which was isolated from decaying seagrass collected at the seashore of Ko Chang (Chang Island), Trat province, Thailand.

\section{Description of Alkalibacterium putridalgicola sp. nov.}

Alkalibacterium putridalgicola [pu.tri.dal.gi'co.la. L. adj. putridus rotten, decayed; L. fem. n. alga seaweed; L. suff. - cola (from L. n. incola) dweller; N.L. n. putridalgicola dweller on putrid marine algae].

Cells are Gram-positive, non-sporulating, straight rods measuring $0.6-0.9 \times 2.7-8.0 \mu \mathrm{m}$, occurring singly, in pairs or in short chains. Motile with peritrichous flagella. Deep colonies in $2.5 \% \mathrm{NaCl}$ GYPF agar medium are pale yellow, opaque and lenticular, with diameters of $1.0-2.0 \mathrm{~mm}$ after 3 days at $30{ }^{\circ} \mathrm{C}$. Surface colonies are round, convex, entire, pale yellow and transparent, with diameters of $0.5-1.0 \mathrm{~mm}$ after 3 days at $30{ }^{\circ} \mathrm{C}$. Aerotolerant. Grows evenly throughout a column of semi-solid agar medium. Catalase- and oxidase-negative. Quinones are not detected (analysed for the type strain). Negative for nitrate reduction and gelatin liquefaction. Ammonia is produced from L-arginine. Slightly halophilic and highly halotolerant; the optimum $\mathrm{NaCl}$ concentration for growth is $2.0-4.0 \%(\mathrm{w} / \mathrm{v})$, with a range of 0.0 to $18.0-20.0 \%(\mathrm{w} / \mathrm{v})$. Alkaliphilic; the optimum $\mathrm{pH}$ for growth is 8.0-9.0, with a range of 6.5-10.0. Growth occurs between -1.8 and $40-45{ }^{\circ} \mathrm{C}$, with an optimum temperature of $37-40{ }^{\circ} \mathrm{C}$. Lactic acid is the major fermentation product from D-glucose; other products are formate, acetate and ethanol with a molar ratio of approximately $2: 1: 1$, without gas formation. Lactate yield decreases at higher $\mathrm{pH}$ of the fermentation medium (analysed for the type strain). DGlucose is metabolized aerobically to acetate in addition to lactate (analysed for the type strain). The fermentation profile of carbohydrates, sugar alcohols and related carbon compounds is given in Table 2. Not inhibited by chloramphenicol or kanamycin; inhibited by ampicillin and trimethoprim. The peptidoglycan type is A4 $\beta$, Orn-DAsp (analysed for the type strain). The major cellular fatty acids are $\mathrm{C}_{16: 0}, \mathrm{C}_{16: 1} \omega 9 c$ and $\mathrm{C}_{18: 1} \omega 9 c$ (oleic acid) (analysed for the type strain). The $\mathrm{G}+\mathrm{C}$ content of the DNA is $41.0-43.0 \mathrm{~mol} \%$ ( $42.5 \mathrm{~mol} \%$ for the type strain).

The type strain is T129-2-1 ${ }^{\mathrm{T}}\left(=\mathrm{DSM} \quad 19182^{\mathrm{T}}=\mathrm{NBRC}\right.$ $103243^{\mathrm{T}}=$ NRIC $0720^{\mathrm{T}}$ ), which was isolated from a decaying marine alga collected at the seashore of Ko Samet (Samet Island), Rayong province, Thailand. Reference strains O26-12-1, O26-12-2 and O26-12-3 were also isolated from decaying marine algae.

\section{Description of Alkalibacterium kapii sp. nov.}

Alkalibacterium kapii [ka'pi.i. N.L. n. kapium ka-pi (a fermented shrimp paste in Thailand); N.L. gen. n. kapii of ka-pi].

Cells are Gram-positive, non-sporulating, straight rods measuring $0.6-1.1 \times 1.8-3.6 \mu \mathrm{m}$, occurring singly, in pairs or in short chains. Motile with peritrichous flagella except for strain T22-1-2 ${ }^{\mathrm{T}}$. Deep colonies in $2.5 \% \mathrm{NaCl}$ GYPF agar medium are creamy yellow, opaque and lenticular, with diameters of $1.0-2.0 \mathrm{~mm}$ after 3 days at $30{ }^{\circ} \mathrm{C}$. Surface colonies are round, convex, entire, creamy yellow and transparent, with diameters of $0.5-1.0 \mathrm{~mm}$ after 3 days at $30{ }^{\circ} \mathrm{C}$. Aerotolerant. Grows evenly throughout a column of semi-solid agar medium. Catalase- and oxidase-negative. Quinones are not detected (analysed for the type strain). Negative for nitrate reduction, gelatin liquefaction and production of ammonia from L-arginine. Slightly halophilic; the optimum $\mathrm{NaCl}$ concentration for growth is 1.5$2.5 \%(\mathrm{w} / \mathrm{v})$, with a range of 0.0 to $19.0-21.0 \%(\mathrm{w} / \mathrm{v})$. Alkaliphilic; the optimum $\mathrm{pH}$ for growth is $8.5-9.0$, with a 
Table 5. Differential characteristics of the novel Alkalibacterium species and phylogenetically related species

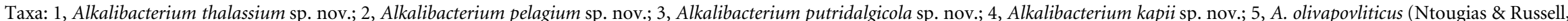

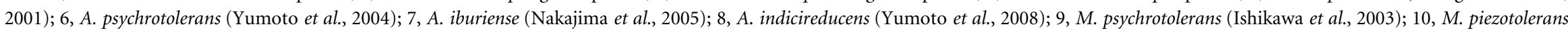

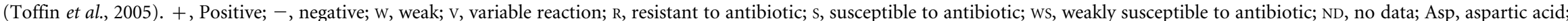
Glu, glutamic acid; Lys, lysine; Orn, ornithine.

\begin{tabular}{|c|c|c|c|c|c|c|c|c|c|c|}
\hline Characteristic & 1 & 2 & 3 & 4 & 5 & 6 & 7 & 8 & 9 & 10 \\
\hline Motility & - & + & + & + (most strains) & $+{ }^{*} \dagger$ & + & + & + & + & - \\
\hline Flagella & - & Peritrichous & Peritrichous & Peritrichous & Peritrichous $^{\star} \dagger$ & Peritrichous & Peritrichous & Peritrichous & Peritrichous & - \\
\hline Colour of colonies & Pale yellow & Pale yellow & Pale yellow & Creamy yellow & Yellowish-white $\ddagger$ & Pale white & Pale white & Pale white & Pale yellow & $\begin{array}{c}\text { Yellowish- } \\
\text { white }^{*} \neq\end{array}$ \\
\hline \multicolumn{11}{|l|}{$\mathrm{NaCl}(\%)$} \\
\hline Range & $0-11$ & $0-17$ & 0 to $18-20$ & 0 to $19-21$ & $0-15$ & $0-17$ & 0 to $14-16$ & $0-15,0-14$ & 0 to $17-20.5$ & $0-12.0$ \\
\hline Optimum & $1-2.5$ & $0.5-1.5$ & $2-4$ & $1.5-2.5$ & $3-5 \S$ & $2-12$ & $3-13$ & $1-11$ & $2-3.75$ & $1.0-2.0$ \\
\hline \multicolumn{11}{|l|}{$\mathrm{pH}$} \\
\hline Range & $7-11$ & $7-11$ & $6.0-6.5$ to 10.0 & $6.5-10.0$ & $8.5-10.8$ & $9-12$ & $9-12$ & $9-12.3$ & $6.0-10.0$ & $5.5-10.0$ \\
\hline Optimum & 9 & $9.0-9.5$ & 8-9 & $8.5-9.0$ & $9.0-10.2$ & $9.5-10.5$ & $9.5-10.5$ & $9.5-11.5$ & $8.5-9.0$ & $7.0-8.0$ \\
\hline \multicolumn{11}{|c|}{ Growth temperature $\left({ }^{\circ} \mathrm{C}\right)$} \\
\hline Range & $10-42.5$ & $10-47.5$ & -1.8 to $40-45$ & $5-10$ to $40-42.5$ & 4 to $35-37$ & $5-45$ & $5-45$ & $15-40,18-37$ & -1.8 to $40-45$ & $4-50$ \\
\hline Optimum & 37 & 37 & $37-40$ & $25-37$ & $27-32$ & 34 & $30-37$ & 20-30 & $37-40$ & $37-40$ \\
\hline \multicolumn{11}{|l|}{ Fermentation of sugars } \\
\hline L-Arabinose & - & + & + & - & - & + & + & ND & + or $\mathrm{w}$ & - \\
\hline D-Xylose & - & + & + & - & - & + & $\mathrm{V}$ & - & + & + \\
\hline Sucrose & + & + & + & + & + & - & $\mathrm{V}$ & $\mathrm{w}$ & + & + \\
\hline Lactose & $\mathrm{w}$ & + & + & - & - & - & $+^{*}$ & $\mathrm{ND}$ & + or $\mathrm{w}$ & $-{ }^{\star}$ \\
\hline Raffinose & $\mathrm{w}$ & $\mathrm{w}$ & + & - & - & - & - & - & $\mathrm{V}$ & $-{ }^{\star}$ \\
\hline D-Salicin & + & + & + & - & $+^{*}$ & $+^{*}$ & $+^{*}$ & ND & $\mathrm{V}$ & $+^{*}$ \\
\hline \multicolumn{11}{|l|}{ Antibiotic sensitivity } \\
\hline $\begin{array}{l}\text { Ampicillin (10 and } \\
25 \mu \mathrm{g})\end{array}$ & s & s & s & s & s & $s^{*}$ & s & s & $s^{*}$ & $s^{*}$ \\
\hline $\begin{array}{l}\text { Chloramphenicol } \\
(2 \mu \mathrm{g})\end{array}$ & $\mathrm{R}$ & $\mathrm{R}$ & $\mathrm{R}$ & $\mathrm{R}$ & s & $\mathrm{Ws}^{*}$ & $\mathrm{R}$ & $\mathrm{R}$ & $\mathrm{R}^{*}$ & $\mathrm{R}^{*}$ \\
\hline $\begin{array}{l}\text { Kanamycin ( } 2 \text { and } \\
10 \mu \mathrm{g})\end{array}$ & $\mathrm{R}$ & $\mathrm{R}$ & $\mathrm{R}$ & $\mathrm{R}$ & s & $\mathrm{R}$ & $\mathrm{R}$ & $\mathrm{R}$ & $\mathrm{R}^{*}$ & $\mathrm{R}^{*}$ \\
\hline $\begin{array}{l}\text { Trimethoprim (10 } \\
\text { and } 25 \mu \mathrm{g})\end{array}$ & $\mathrm{R}$ & s & s & $\mathrm{R}$ & s & $s^{*}$ & $\mathrm{R}$ & $\mathrm{R}$ & $\mathrm{R}^{*}$ & $\mathrm{R}^{*}$ \\
\hline $\mathrm{NH}_{3}$ from L-arginine & - & - & + & - & $\mathrm{w}^{\star}$ & $\mathrm{W}^{*}$ & $\mathrm{~W}^{*}$ & $\mathrm{ND}$ & $\mathrm{w}$ & $\mathrm{w}^{*}$ \\
\hline Peptidoglycan type & $\begin{array}{c}\text { A4 } \beta, \\
\text { Orn-D-Asp }\end{array}$ & $\begin{array}{c}\text { A4 } \beta, \\
\text { Orn-D-Asp }\end{array}$ & $\begin{array}{c}\mathrm{A} 4 \beta \\
\text { Orn-D-Asp }\end{array}$ & $\begin{array}{c}\mathrm{A} 4 \beta \\
\text { Orn-D-Glu }\end{array}$ & $\begin{array}{c}\mathrm{A} 4 \beta \\
\text { Orn-D-Asp }\end{array}$ & $\begin{array}{c}\text { A4 } 4 \alpha \\
\text { Lys (Orn)- } \\
\text { D-Asp }\end{array}$ & $\begin{array}{c}\text { A4 } \alpha, \\
\text { Lys-D-Asp }\end{array}$ & $\begin{array}{c}\text { A4 } \alpha \\
\text { Lys (Orn)- } \\
\text { D-Asp }\end{array}$ & $\begin{array}{c}\mathrm{A} 4 \beta, \\
\text { Orn-D-Glu }\end{array}$ & $\mathrm{ND}$ \\
\hline
\end{tabular}




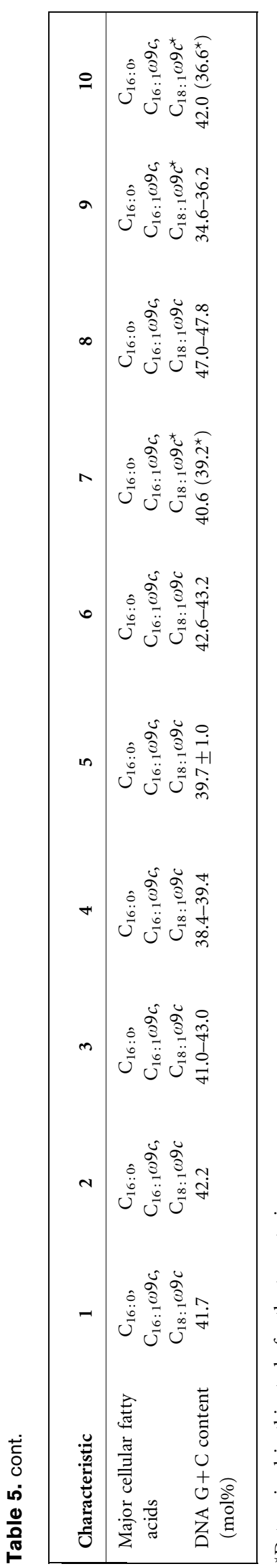

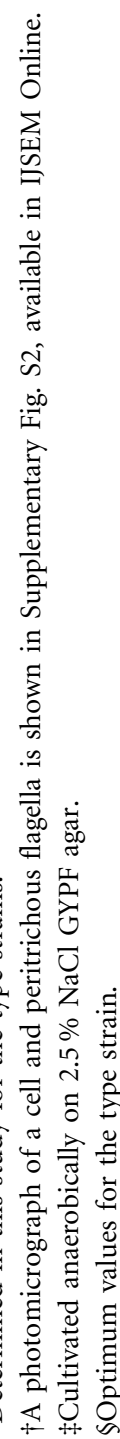

range of 6.0-6.5 to 10.0. Growth occurs between 5-10 and $40-42.5{ }^{\circ} \mathrm{C}$, with an optimum temperature of $25-37^{\circ} \mathrm{C}$. Lactic acid is the major fermentation product from $\mathrm{D}$ glucose; other products are formate, acetate and ethanol with a molar ratio of approximately $2: 1: 1$, without gas formation. Lactate yield decreases at higher $\mathrm{pH}$ of the fermentation medium (analysed for the type strain). Carbohydrates and related compounds are metabolized aerobically to acetate in addition to lactate (analysed for the type strain). The fermentation profile of carbohydrates, sugar alcohols and related carbon compounds is given in Table 2. Not inhibited by chloramphenicol, kanamycin or trimethoprim; inhibited by ampicillin. The peptidoglycan type is A4 $\beta$, Orn-D-Glu (analysed for the type strain). The major cellular fatty acids are $\mathrm{C}_{16: 0}, \mathrm{C}_{16: 1} \omega 9 c$ and $\mathrm{C}_{18: 1} \omega 9 c$ (oleic acid) (analysed for the type strain). The $\mathrm{G}+\mathrm{C}$ content of the DNA is $38.4-39.4 \mathrm{~mol} \%$ (39.4 $\mathrm{mol} \%$ for the type strain).

The type strain is T22-1-2 $2^{\mathrm{T}} \quad\left(=\mathrm{DSM} \quad 19180^{\mathrm{T}}=\mathrm{NBRC}\right.$ $103247^{\mathrm{T}}=$ NRIC $0724^{\mathrm{T}}$ ), which was isolated from 'ka-pi' (a salted and fermented shrimp paste) obtained at a market near Bangkok, Thailand. Reference strains T78-1-2, T82-5-1 and T171-1-1 were isolated from 'ka-pi', salted fish and raw fish.

\section{Acknowledgements}

The authors wish to thank the Japan Bioindustry Association (Tokyo, Japan) for supporting part of this study. We are grateful to Kazuo Komagata for support to conduct this study and Yasutaka Tokuda for kind help in collecting samples in Okinawa.

\section{References}

Axelsson, L. T. (1993). Lactic acid bacteria: classification and physiology. In Lactic Acid Bacteria, pp. 1-63. Edited by S. Salminen \& A. von Wright. New York: Marcel Dekker.

Carlsson, J. \& Griffith, C. J. (1974). Fermentation products and bacterial yields in glucose-limited and nitrogen-limited cultures of streptococci. Arch Oral Biol 19, 1105-1109.

Fukui, K., Kato, K., Komada, T., Ohta, H., Shimamoto, T. \& Shimono, T. (1988). Kinetic study of a change in intracellular ATP level associated with aerobic catabolism of ethanol by Streptococcus mutans. J Bacteriol 170, 4589-4593.

Gunsalus, I. C. \& Niven, C. F., Jr (1942). The effect of $\mathrm{pH}$ on the lactic acid fermentation. J Biol Chem 145, 131-136.

Ishikawa, M., Nakajima, K., Yanagi, M., Yamamoto, Y. \& Yamasato, K. (2003). Marinilactibacillus psychrotolerans gen. nov., sp. nov., a halophilic and alkaliphilic marine lactic acid bacterium isolated from marine organisms in temperate and subtropical areas of Japan. Int J Syst Evol Microbiol 53, 711-720.

Ishikawa, M., Nakajima, K., Itamiya, Y., Furukawa, S., Yamamoto, Y. \& Yamasato, K. (2005). Halolactibacillus halophilus gen. nov., sp. nov. and Halolactibacillus miurensis sp. nov., halophilic and alkaliphilic marine lactic acid bacteria constituting a phylogenetic lineage in Bacillus rRNA group 1. Int J Syst Evol Microbiol 55, 2427-2439.

Jones, B. E., Grant, W. D., Collins, N. C. \& Mwatha, W. E. (1994). Alkaliphiles: diversity and identification. In Bacterial Diversity and Systematics, pp. 195-230. Edited by F. G. Priest, A. RamosCormenzana \& B. J. Tindall. New York: Plenum Press. 
Kushner, D. J. (1978). Life in high salt and solute concentrations: halophilic bacteria. In Microbial Life in Extreme Environments, pp. 318-346. Edited by D. J. Kushner. London: Academic Press.

Kushner, D. J. \& Kamekura, M. (1988). Physiology of halophilic eubacteria. In Halophilic Bacteria, vol. I, pp. 109-140. Edited by F. Rodríguez-Valera. Boca Raton, FL: CRC Press.

Liu, J.-R., Tanner, R. S., Schumamm, P., Weiss, N., McKenzie, C. A., Janssen, P. H., Seviour, E. M., Lawson, P. A., Allen, T. D. \& Seviour, R. J. (2002). Emended description of the genus Trichococcus, description of Trichococcus collinsii sp. nov., and reclassification of Lactosphaera pasteurii as Trichococcus pasteurii comb. nov. and Ruminococcus palustris as Trichococcus palustris comb. nov. in the low-G + C Grampositive bacteria. Int J Syst Evol Microbiol 52, 1113-1126.

Nakajima, K., Hirota, K., Nodasaka, Y. \& Yumoto, I. (2005). Alkalibacterium iburiense sp. nov., an obligate alkaliphile that reduces an indigo dye. Int J Syst Evol Microbiol 55, 1525-1530.

Niimura, Y., Koh, E., Uchimura, T., Ohara, N. \& Kozaki, M. (1989). Aerobic and anaerobic metabolism in a facultative anaerobe Ep01 lacking cytochrome, quinone and catalase. FEMS Microbiol Lett 61, 79-84.

Niimura, Y., Koh, E., Yanagida, F., Suzuki, K., Komagata, K. \& Kozaki, M. (1990). Amphibacillus xylanus gen. nov., sp. nov., a facultatively anaerobic sporeforming xylan-digesting bacterium which lacks cytochrome, quinone, and catalase. Int J Syst Bacteriol 40, 297-301.
Ntougias, S. \& Russell, N. (2001). Alkalibacterium olivoapovliticus gen. nov., sp. nov., a new obligately alkaliphilic bacterium isolated from edible-olive wash-waters. Int J Syst Evol Microbiol 51, 1161-1170.

Rhee, S. K. \& Park, M. Y. (1980). Effect of environmental pH on fermentation balance of Lactobacillus bulgaricus. J Bacteriol 144, $217-$ 221.

Sakamoto, M. \& Komagata, K. (1996). Aerobic growth of and activities of NADH oxidase and NADH peroxidase in lactic acid bacteria. J Ferment Bioeng 82, 210-216.

Toffin, L., Zink, K., Kato, C., Pignet, P., Bidault, A., Bienvenu, N., Birrien, J.-L. \& Prieur, D. (2005). Marinilactibacillus piezotolerans sp. nov., a novel marine lactic acid bacterium isolated from deep subseafloor sediment of the Nankai Trough. Int J Syst Evol Microbiol 55, 345-351.

Yamada, T. \& Carlsson, J. (1975). Regulation of lactate dehydrogenase and change of fermentation products in streptococci. J Bacteriol 124, 55-61.

Yumoto, I., Hirota, K., Nodasaka, Y., Yokota, Y., Hoshino, T. \& Nakajima, K. (2004). Alkalibacterium psychrotolerans sp. nov., a psychrotolerant obligate alkaliphile that reduces indigo dye. Int J Syst Evol Microbiol 54, 2379-2383.

Yumoto, I., Hirota, K., Nodasaka, Y., Tokiwa, Y. \& Nakajima, K. (2008). Alkalibacterium indicireducens sp. nov., an obligate alkaliphile that reduces indigo dye. Int J Syst Evol Microbiol 58, 901-905. 